\title{
Correction to: Extracellular Microvesicles Released From Brain Endothelial Cells are Detected in Animal Models Of HIV-1 Signifying Unresolved Inflammation
}

\author{
Servio H. Ramirez ${ }^{1,2,3}$. Tetyana P. Buzhdygan ${ }^{1,2}$. Jonathan F. Hale ${ }^{1}$. Liang Cheng ${ }^{5,6}$. Guangming $\mathrm{Li}^{4,5}$. \\ Bryson Hoover-Hankerson ${ }^{1} \cdot$ Roshanak Razmpour $^{1} \cdot$ Uma Sriram $^{1} \cdot$ Lishan Su ${ }^{4,5} \cdot$ Raghava Potula $^{1,2}$. \\ Allison M. Andrews ${ }^{1,2}$ (B) \\ Published online: 1 October 2021 \\ (c) Springer Science+Business Media, LLC, part of Springer Nature 2021
}

Correction to: Journal of Neuroimmune Pharmacology https://doi.org/10.1007/s11481-021-10008-5

In this article the wrong figure appeared as Fig. 2; the figure should have appeared as shown below.

The original article has been corrected.

The original article can be found online at https://doi.org/10.1007/ s11481-021-10008-5.

Allison M. Andrews

Allison.andrews@temple.edu

1 Department of Pathology \&, Laboratory Medicine Lewis, Katz School of Medicine at Temple University, 3500 N, Broad St, Philadelphia, PA 19140, USA

2 School of Medicine at, The Center for Substance Abuse Research Lewis Katz, Temple University, 3500 N Broad St, Philadelphia, PA 19140, USA

3 The Shriners Hospitals Pediatric Research Center, Philadelphia, PA 19140, USA

4 Division of Virology, Pathogenesis and Cancer, Institute of Human Virology, Departments of Pharmacology, University of Maryland School of Medicine, Baltimore, MD 21201, USA

5 Lineberger Comprehensive Cancer Center, Department of Microbiology and Immunology, The University of North Carolina At Chapel Hill, Chapel Hill, NC 27599, USA

6 Frontier Science Center for Immunology and Metabolism, Medical Research Institute, Wuhan University,

Wuhan 430071, China 
A

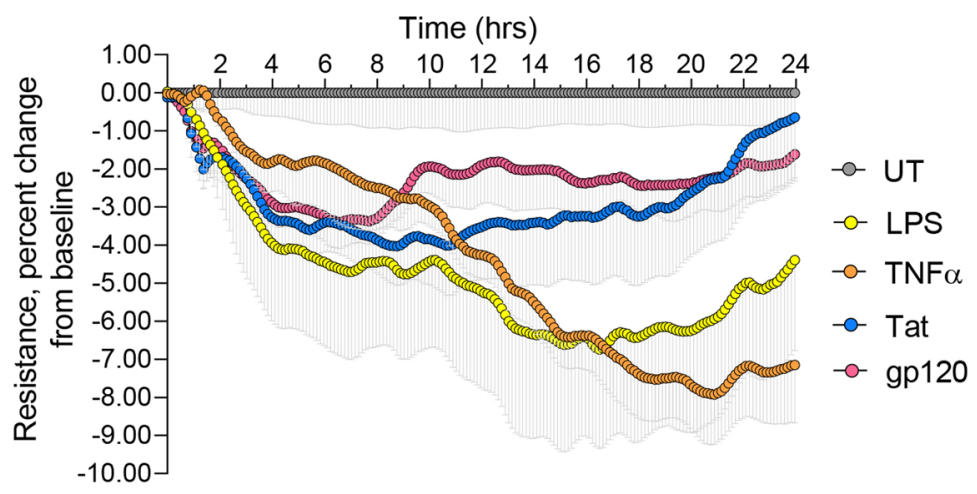

B

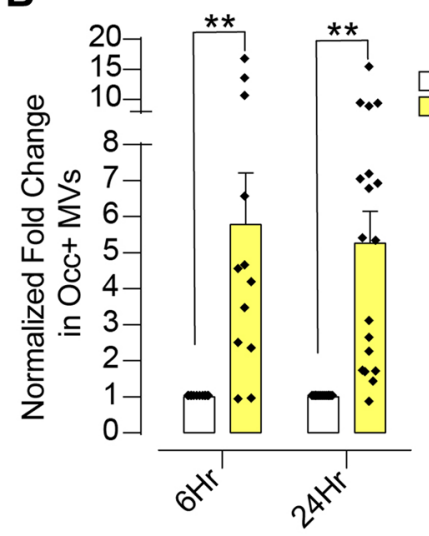

D

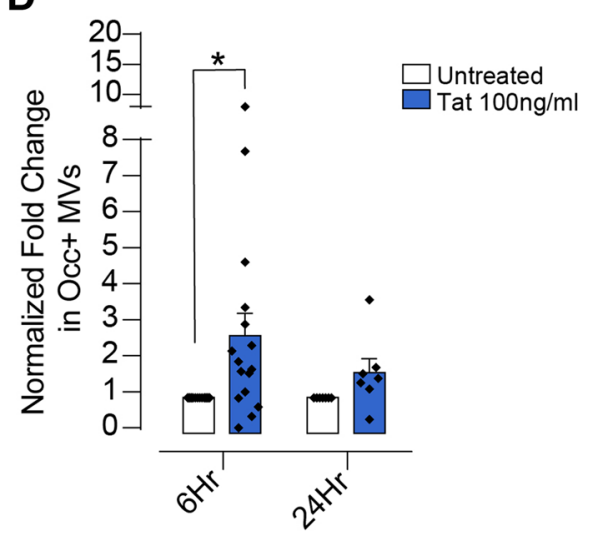

C

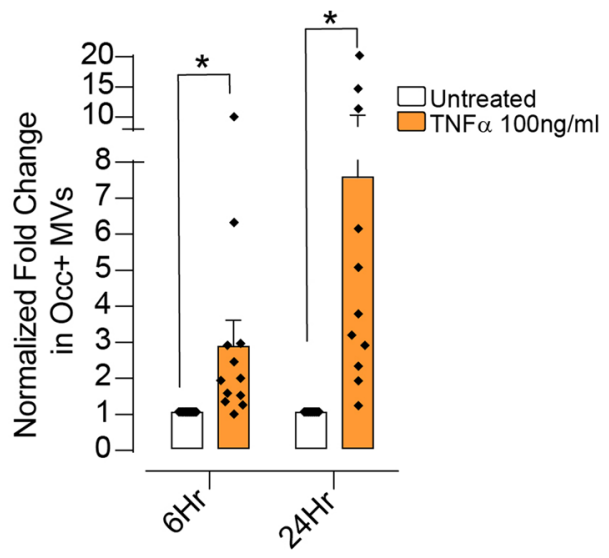

E

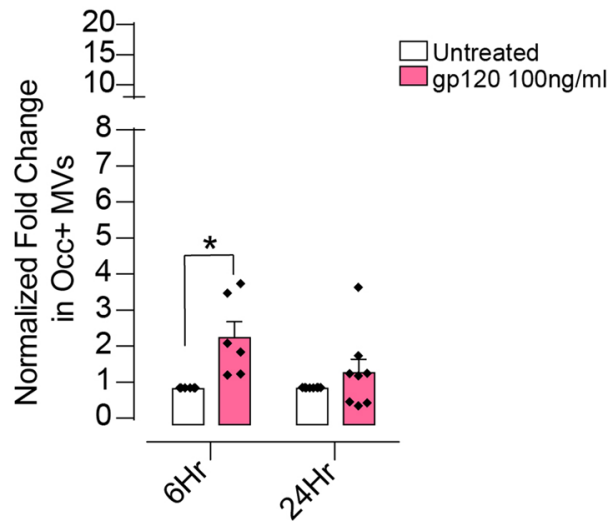

Publisher's Note Springer Nature remains neutral with regard to jurisdictional claims in published maps and institutional affiliations. 